\title{
Agricultura de corte e queima e alternativas agroecológicas na Amazônia
}

\section{Slash and burn agriculture and agroecological alternatives in the amazon}

Anna Karyne Costa Rego - Mestre em Ciências Florestais pela Universidade Federal Rural da Amazônia/UFRA, Programa de Pós-Graduação em Ciências Florestais. Professora da Universidade Federal Rural da Amazônia/UFRA. E-mail: anna.kcosta@hotmail.com.

Osvaldo Ryohei Kato - Doutor em Agricultura Tropical pela Universitat Goettingen, Alemanha. Pesquisador A na Embrapa Amazônia Oriental. E-mail: osvaldo.kato@ embrapa.br

\section{Resumo}

Esse artigo tem por objetivo apresentar a principal forma de uso do solo pelos agricultores da Amazônia, bem como as alternativas de produção baseadas nos princípios agroecológicos por meio de levantamento bibliográfico. A expansão da agricultura e da pecuária é identificada como a principal causa do desmatamento na região devido ao corte e a queima da vegetação como principal forma de preparo de áreas para o cultivo. Essa prática consiste em derrubar e queimar a vegetação para a implantação de cultivos agrícolas por dois ou três anos, posteriormente a área é deixada em pousio para o restabelecimento da vegetação secundária e para que o solo retome sua capacidade produtiva. No entanto, com o crescimento populacional e a necessidade de geração de alimentos, essa prática tornou-se insustentável devido apresentar períodos de pousio cada vez mais curtos. Com isso, o desenvolvimento de novas formas de cultivo sustentável tornou-se necessário.

\section{Palavras-chave}

Uso do Solo. Agricultura. Desmatamento. Cultivo Sustentável.

\begin{abstract}
This article aims to present the main form of land use by farmers in the Amazon, as well as production alternatives based on agroecological principles through a literature review. Agriculture is identified as the main cause of deforestation in the region due slash and burn of vegetation as the main form of land preparation for farming. This practice consists in slashing and burning vegetation for the deployment of crops for two or three years, posteriorly the land is leave at fallow to the secondary vegetation establishment and soil recapture their productive capacity. However, with population growth and the need to generate food this practice became unsustainable due presents fallow periods increasingly shorter. Thus, the development of new forms of sustainable crop has become necessary.
\end{abstract}

\section{Keywords}

Land Use. Agriculture. Deforestation. Sustainable Farming. 


\section{INTRODUÇÃO}

Nas décadas de 1960 e 1970, os Planos de Desenvolvimento da Amazônia (PDA) foram direcionados para favorecer a implantação de grandes projetos agrícolas e pecuários (FEARNSIDE, 1997). Nesse mesmo período, começaram a serem criados os projetos de colonização na região, com o objetivo de integrar economicamente essa região ao restante do país (SANTOS, 2008). Os projetos de colonização atraíram milhares de famílias de pequenos produtores para a Amazônia (SANTOS, 2008). Boa parte dessa população é de agricultores com estabelecimentos de pequeno e médio porte (agricultura familiar) com até 200 ha (HURTIENNE, 2005) que ao longo dos anos têm praticado o corte e a queima da vegetação para o estabelecimento de cultivos agrícolas e pastos.

A expansão da agricultura e da pecuária na Amazônia tem sido considerada a principal causa do desmatamento na região (CATTANEO, 2002). Entre as consequências desse processo de expansão da fronteira agrícola e ocupação da região, destaca-se a aceleração do desmatamento e da pobreza rural (MMA, 2000). Os planos de expansão da agricultura na Amazônia preconizavam a adoção de insumos modernos nos sistemas de produção, nos moldes da revolução verde (SANTOS, 2008).

Esse artigo tem por objetivo apresentar a principal forma de uso do solo pelos agricultores na Amazônia, a agricultura de derruba e queima, bem como as alternativas de produção baseadas nos princípios agroecológicos por meio de levantamento bibliográfico. Em primeiro lugar, é feita uma abordagem sobre uso da terra pela agricultura e impactos ambientais causados. Em seguida, é dada atenção especial aos estudos que analisam alternativas de produção sustentável e as transformações nas formas de uso do solo. Por fim, são apresentados sistemas de produção exitosos que vêm sendo utilizados como alternativas à forma tradicional de cultivo, a fim de promover sua sustentabilidade por meio de tecnologias de baixo impacto e fonte de renda para os agricultores da Amazônia.

\section{AGRICULTURA DE CORTE E QUEIMA NA AMAZÔNIA}

Entre as diversas formas de uso do solo na Amazônia, destaca-se a agricultura de subsistência, praticada por agricultores em pequena escala, por meio do corte e queima da floresta primária ou secundária para fins agrícolas (FREITAS et al., 2013). Este sistema produtivo é o que prevalece na região, para formação de roças (OLIVEIRA et al., 2007), onde se alterna períodos de cultivo e de pousio, quando a vegetação secundária (capoeira) se desenvolve por meio de 
rebrotas de tocos, raízes e sementes que sobrevivem ao corte e à queimada, para após algum tempo, ser transformada em fertilizante para o próximo período de cultivo (KATO et. al., 2014).

Essa prática busca suprir as necessidades nutricionais das culturas com os nutrientes acumulados na vegetação secundária (MARCOLAN; LOCATELLI; FERNANDES, 2009). No entanto, a queima da vegetação propicia a perda de nutrientes retidos na biomassa (KANASHIRO; DENICH, 1998). Essa forma de cultivo interrompe a reciclagem e os nutrientes que seriam adicionados gradativamente ao solo, pela decomposição da matéria orgânica, passam a ficar disponíveis de uma só vez, nas cinzas sobre a superfície do solo (MARCOLAN; LOCATELLI; FERNANDES, 2009). A agricultura de corte e queima torna-se insustentável na medida em que são feitas repetidas queimadas, o que reduz o tempo de pousio entre os cultivos (DENICH; KANASHIRO; VLEK, 1999). Este sistema de cultivo necessita de pousios longos (sete a dez anos) para ser sustentável em termos produtivos (KATO, O. et al., 2014).

A sustentabilidade desse sistema de cultivo é baseada na fertilidade natural dos solos, que foi colocada em risco pela intensificação do processo de ocupação da Amazônia (MIRANDA; RODRIGUES 1999). As queimadas constantes representam uma contínua extração de nutrientes minerais e redução da matéria orgânica do solo a qual leva à degradação do solo e ao declínio da produtividade, além de provocar alterações no comportamento hídrico e fotossintético de espécies componentes da vegetação, emissão de gases do efeito estufa e riscos de incêndios acidentais (HOLSCHER et al., 1997). Além disso, é considerada a principal fonte de desmatamento (ARCO-VERDE; AMARO, 2012).

Neste contexto, os agricultores familiares são prejudicados com a perda de produtividade agrícola, e na maioria das vezes não dispõem de recursos financeiros suficientes para a recuperação da fertilidade do solo da propriedade, ficando impossibilitados de obter renda a partir da atividade agrícola. Com isso, muitos agricultores acabam migrando para novas fronteiras agrícolas.

Tendo em vista a redução da capacidade produtiva do solo ocasionada pela prática de corte e queima, é necessário o uso de novos sistemas produtivos de alimentos onde a produção seja feita de forma diversificada e sustentável.

\section{TRANSIÇÃO PRODUTIVA E A AGROECOLOGIA}

O processo de modernização da agricultura causou efeitos danosos, em particular, no mundo rural e sobre a sociedade de forma geral. O processo de mecanização do campo provocou sérios danos ambientais (JESUS et al., 2011; 
FONTES et al., 2013; FREITAS et al., 2014), como: destruição das florestas, erosão dos solos (FREITAS et al., 2014), além da contaminação dos alimentos e sérios conflitos sociais no Brasil, o aumento da concentração da posse de terra, concentração da pobreza nas áreas rurais, o êxodo rural e o desemprego (FREITAS et al., 2014). Esse modelo de agricultura afetou diretamente os centros urbanos, o modo e a qualidade de vida da sociedade, além de criar dificuldades para a geração de renda das populações (FONTES et al., 2013), colocou em risco os ecossistemas (FONTES et al., 2013) e a perdas de solos (JESUS et al., 2011).

Há vários anos a sociedade busca estabelecer estilos de agricultura que sejam menos danosos ao meio ambiente e capazes de manter os recursos naturais, assegurar maior longevidade produtiva, tentando fugir do estilo convencional de agricultura que passou a ser hegemônico a partir dos novos descobrimentos da química agrícola, da biologia e da mecânica ocorridos a partir do final do século XIX (CAPORAL; COSTABEBER, 2007).

$\mathrm{Na}$ busca e construção de novos conhecimentos, surge a Agroecologia, de modo que seus princípios passam a contribuir para o estabelecimento de um novo caminho para a construção de agriculturas de base ecológica e sustentáveis (CAPORAL; PAULUS; COSTABEBER, 2009). A Agroecologia nasceu, como novo enfoque científico, capaz de dar suporte a uma transição a estilos de agriculturas sustentáveis e, portanto, contribuir para o estabelecimento de processos de desenvolvimento rural sustentável (JESUS et al., 2011).

Além de produzir sem agrotóxicos a Agroecologia trabalha com o manejo ecológico dos agroecossistemas priorizando a manutenção contínua da fertilidade dos solos. Encontra-se destinada à subsistência e a qualidade de vida do produtor rural e de sua família, não deixando de lado a inserção dos seus produtos num mercado que é cada vez maior e atua com relações mais solidárias (FREITAS et al., 2014).

Tem-se confundido a Agroecologia com um modelo de agricultura (CAPORAL; PAULUS; COSTABEBER, 2009). Também é comum confundir Agroecologia com a simples adoção de determinadas práticas ou tecnologias agrícolas ambientalmente mais adequadas ou com uma agricultura que não usa agrotóxicos ou, simplesmente, com a substituição de insumos (ALTIERI; ROSSET, 2002).

A agroecologia, segundo Altieri (1989), é definida como ciência ou disciplina científica que apresenta uma série de princípios, conceitos e metodologias para estudar, analisar, dirigir, desenhar e avaliar agroecossistemas, com a finalidade de permitir a implantação e o desenvolvimento de estilos de agricultura com maiores níveis de sustentabilidade. 
Segundo Caporal e Costabeber (2007), a agroecologia é capaz de realizar a transição dos atuais modelos de desenvolvimento rural e de agricultura convencional, para estilos de desenvolvimento rural e de agriculturas sustentáveis. Isso ocorre por ela ser uma ciência que por meio de seus princípios e conceitos, é capaz de gerar metodologias para a superação do modelo da revolução verde, por meio do resgate, valorização e novas formas de se fazer agricultura (FONTES et al., 2013).

A adesão ao enfoque agroecológico não supõe pleitear ou defender uma nova "revolução modernizadora", mas sim uma ação dialética transformadora, como já vem ocorrendo ao longo de um horizonte temporal. Este processo modernizador, parte do conhecimento local, respeitando e incorporando o saber popular e buscando integrá-lo com o conhecimento científico, para dar lugar à construção e à expansão de novos saberes socioambientais, alimentando assim, permanentemente, o processo de transição agroecológica (CAPORAL; PAULUS; COSTABEBER, 2009).

A agroecologia proporciona as bases científicas para apoiar o processo de transição para uma agricultura "sustentável" nas suas diversas manifestações e/ou denominações (ALTIERI, 1989). Para Nunes da Silva et al., (2009), os processos de transição agroecológica constituem-se em desafios para a sustentabilidade das regiões rurais. A transição agroecológica não implica somente numa maior racionalização econômico-produtiva com base nas especificidades biofísicas de cada agroecossistema, mas também numa mudança nas atitudes e valores dos atores sociais em relação ao manejo e conservação dos recursos naturais (COSTABEBER, 1998).

Gliessman (2001) distinguiu três níveis fundamentais no processo de transição para agroecossistemas mais sustentáveis. O primeiro nível diz respeito ao incremento da eficiência das práticas convencionais para reduzir o uso e consumo de inputs externos caros, escassos e daninhos ao meio ambiente. O segundo nível da transição se refere à substituição de inputs e práticas convencionais por práticas alternativas. A meta seria a substituição de insumos e práticas intensivas contaminantes e degradadoras do meio ambiente por outras mais benignas sob o ponto de vista ecológico. Neste nível da transição a estrutura básica do agroecossistema seria pouco alterada, podendo ocorrer, então, problemas similares aos que se verificam nos sistemas convencionais. $\mathrm{O}$ terceiro e mais complexo nível da transição é representado pelo redesenho dos agroecossistemas, para que estes funcionem com base em um novo conjunto de processos ecológicos. 


\section{SISTEMAS PRODUTIVOS BASEADOS NOS PRINCÍPIOS AGROECOLÓGICOS}

\subsection{MANEJO DE CAPOEIRA: SISTEMA DE CORTE E TRITURAÇÃO COMO ALTERNATIVA AGROECOLÓGICA}

A necessidade de se buscar práticas sustentáveis que substituam o corte e a queima da capoeira no preparo da área estimulou o desenvolvimento de iniciativas de transição do modelo convencional de agricultura para formas mais sustentáveis (CORRÊA, 2011). O manejo da capoeira é um bom exemplo: antes tratado sob a lógica de corte e queima e, hoje, com possibilidades de incorporação de uma nova tecnologia capaz de triturar a biomassa aérea dessas vegetações (SAMPAIO; KATO; NASCIMENTO E SILVA, 2008). O empenho da comunidade científica em buscar novas tecnologias de produção resultou no sistema de plantio direto na capoeira ou tecnologia de corte e trituração da capoeira sem queima, desenvolvido pela Embrapa Amazônia Oriental em parceria com as universidades alemãs de Göttingen e de Bonn (KATO, M. et al., 1999; KATO, O. et al., 2007).

Segundo Sampaio, Kato e Nascimento e Silva (2008), o sistema agrícola cultivado com a técnica de corte e trituração da capoeira está associado a duas inovações tecnológicas: enriquecimento de capoeira - plantio de leguminosas arbóreas de crescimento rápido visando diminuir o período de pousio e acumular biomassa na vegetação de pousio (BRIENZA JÚNIOR et al., 2000) e a trituração de capoeira - que consiste na trituração da biomassa aérea da vegetação de pousio (capoeira) para reduzir a perda de nutrientes, adicionar matéria orgânica e formar uma cobertura morta do solo (KATO, O; SECCO, N. 2004).

Os estudos baseados no corte e na trituração da capoeira apontam tendências de aumento da matéria orgânica do solo favorecendo o restabelecimento de níveis desejáveis de fertilidade do solo, ainda que sejam utilizadas pequenas doses de fertilizantes nos primeiros anos de implantação do sistema para suprir a carência de nutrientes nessa fase (KATO, M. 1998; GAMA, 2002; COELHO et al., 2004).

Esse sistema proporciona a recuperação gradual do solo pela oferta de nutrientes e carbono por meio da reciclagem de nutrientes das camadas profundas para a superfície e fornecimento de matéria orgânica pela deposição da folhagem, melhorias nas propriedades químicas e físicas do solo, oferta de serviços ambientais e flexibilização do calendário agrícola (TRINDADE et al., 2011).

Para Marcolan, Locatelli e Fernandes (2009), o preparo da área usando a técnica de corte e trituração da vegetação poderá, além de reduzir a poluição 
ambiental e os riscos de incêndios acidentais, evitar as perdas de nutrientes acumulados na biomassa e proteger o solo contra os efeitos da lixiviação e da erosão, reduzindo os gastos com adubação e melhorando os atributos físicos, químicos e biológicos do solo.

No manejo com a vegetação secundária triturada, os resíduos vegetais são mantidos na superfície do solo, enquanto que, no sistema com a queima da vegetação secundária, o solo fica exposto à degradação pelo impacto das gotas das chuvas e pela ação do fogo, diminuindo a estabilidade do solo e como consequência ocorre a diminuição da qualidade estrutural do solo, proporcionando aumento da densidade e da resistência à penetração (MARCOLAN; LOCATELLI; FERNANDES, 2009).

Souza et al. (2011), verificaram que o sistema de manejo com corte e trituração da capoeira propiciou condições favoráveis ao desenvolvimento radicular na camada mais superficial do solo, com menor resistência à penetração, em relação ao manejo de derruba e queima da capoeira.

Os agroecologistas argumentaram durante anos que os novos modelos de agricultura que a humanidade vai precisar no futuro imediato devem ser enraizados na lógica ecológica da agricultura de pequena escala tradicional, que representa formas já estabelecidas, bem sucedidas e adaptáveis de agricultura (ALTIERI, 2004). No sistema sem queima, as vantagens são bastante nítidas e aos poucos o sistema de manejo da capoeira tradicional de corte e queima vem sendo substituído pela moderna prática de corte e trituração, porém de forma lenta e reticente (SAMPAIO; KATO; NASCIMENTO E SILVA, 2007).

$\mathrm{Na}$ Região Amazônica, particularmente, as alternativas tecnológicas ao uso do fogo disponíveis hoje têm se mostrado promissoras, embora seus resultados ainda sejam incipientes, principalmente porque não têm sido incluídas em políticas de uso da terra e nos instrumentos econômicos de financiamento à produção (PEREIRA; VIEIRA, 2001; SÁ et al., 2006).

\subsection{SISTEMAS AGROFLORESTAIS COMO ALTERNATIVA DE PRODUÇÃO SUSTENTÁVEL}

\subsubsection{Definição e classificação dos sistemas agroflorestais}

A definição dos sistemas agroflorestais, tipos e manejos são resultantes de diversas pesquisas e práticas, o que inclui processos de sucessão ecológica, conceitos de sustentabilidade e agroecologia (ALVES, 2009). 
São muitas as definições sobre sistemas agroflorestais (SAF), entre as quais, pode-se citar as de Nair (1989) e Medrado (2000). Nair (1989) define os sistemas agroflorestais como sistemas de produção nos quais árvores são associadas com espécies agrícolas e/ou animais, podendo apresentar vários arranjos em espaço e tempo. Para Medrado (2000), são sistemas de manejo sustentado da terra que aumenta o seu rendimento, combinando o plantio de espécies florestais com cultivos agrícolas e/ou animais, simultânea ou consecutivamente, de forma definida, na mesma unidade de terreno, envolvendo práticas de manejo de acordo com a população local.

A classificação dos sistemas agroflorestais varia de acordo com a composição, condição, situação e propósito ou função a que se determina a atividade (SILVA, 2013). No entanto, a classificação mais utilizada está relacionada com a natureza dos componentes, podendo, os SAF serem classificados em silviagrícola, quando envolve o consórcio de espécies arbóreas e culturas agrícolas; silvipastoril, quando o consórcio envolve espécies arbóreas e animais; e agrossilvipastoril quando o consórcio se dá entre espécies arbóreas, culturas agrícolas e animais (MARTINS, 2013).

\subsubsection{Vantagens de produzir através de SAF}

Estes sistemas apresentam inúmeras vantagens, seja do ponto de vista ecológico, econômico e social, por serem considerados sustentáveis, visto que contribuem para a qualidade do meio ambiente; gerando renda aos agricultores e por integrarem homens e mulheres em suas atividades, possibilitando a participação de todos no processo produtivo (VIEIRA et al., 2008).

Para Engel (1999), o objetivo principal dos SAF é otimizar o uso da terra, conciliando a produção florestal com a produção de alimentos, conservando o solo e diminuindo a pressão pelo uso da terra para produção agrícola. ArcoVerde (2008) apresentou como objetivos dos SAF a contribuição para a segurança alimentar e o bem-estar social e econômico dos produtores rurais, particularmente aqueles de baixa renda, assim como para a manutenção dos recursos naturais. Paludo e Costabeber (2012) observaram os princípios agroecológicos dos SAF e constataram que eles têm por objetivo harmonizar os agroecossistemas com os processos dinâmicos dos ecossistemas naturais.

Em comparação aos sistemas convencionais de uso do solo, os SAF apresentam como principal vantagem o aproveitamento mais eficiente dos recursos naturais obtido através da otimização do uso da energia solar pelas plantas devido à estratificação dos componentes, pela ciclagem de nutrientes, 
pela manutenção da umidade do solo e pela proteção do solo contra erosão (ALVES, 2009).

A combinação de árvores com cultivos anuais ou pastagens fazem com que os SAF tenham o potencial de diminuir a degradação do solo, diversificar a renda, diminuir a pressão sobre as áreas florestais remanescentes (SMITH et al., 1998), produzir várias culturas ao mesmo tempo e minimizar o risco de perdas (VANDERMEER, 1989).

Os sistemas agroflorestais proporcionam a melhoria da estrutura e da fertilidade dos solos e promovem uma maior eficiência na ciclagem de nutrientes promovida pelas raízes dos componentes arbóreos, arbustivos e herbáceos (ALVES, 2009). A utilização de diferentes espécies proporciona um melhor aproveitamento da área, aliando interesses conservacionistas e econômicos.

Com o aumento da biodiversidade no sistema de produção, os sistemas agroflorestais podem ser considerados uma boa alternativa para utilização de recursos que aumentam a produtividade, proporcionando maior nível de sustentabilidade, (LAMÔNICA; BARROSO, 2008). Alves (2009) observou que a diversidade é fundamental para a estabilidade biológica e econômica em todos os modelos de SAF.

Segundo Noronha (2008) e May e Trovatto (2008) estes sistemas têm demonstrado enorme potencial para produzir sustentavelmente grande diversidade vegetal e até animal. Assim, poer meio dos SAF obtém-se uma importante ferramenta para a agricultura familiar no combate à pobreza rural, na garantia da segurança alimentar e na conservação dos recursos naturais.

A condição de sustentabilidade nesses sistemas deve está vinculada tanto às necessidades, anseios e possibilidades do produtor, como às exigências agroecológicas das espécies a serem combinadas e às limitações do ambiente (SILVA, 2014). Nesse sentido, pode-se afirmar que a condição efetiva de sustentabilidade é determinada pela integração de fatores condicionantes da biologia, economia e ecologia que favoreçam sua adotabilidade pelos agricultores (SILVA, 2014). Abdo, Valeri e Martins (2008), consideram os sistemas agroflorestais como uma opção interessante e extremamente viável para o pequeno produtor (ABDO; VALERI; MARTINS, 2008). No entanto, o agricultor deve escolher uma variedade de espécies adaptadas à região e promover uma boa interação entre elas (ABDO; VALERI; MARTINS, 2008).

Nesse sentido, a sustentabilidade pode ser entendida como a consequência direta do desempenho de sistemas tecnicamente bem formulados, economicamente viáveis e ambientalmente adequados. 
Silva (2014) estabelece que para os fatores biológicos e ecológicos, devem prevalecer as seguintes premissas: foco nas espécies a serem associadas e no ambiente; adequação à condição agroecológica; completaridade entre os componentes do sistema e conservação do ambiente produtivo (água, solo, microclima).

\subsubsection{SAF como Mecanismos de Desenvolvimento Limpo (MDL)}

As mudanças climáticas causadas pelas alterações nas concentrações de Gases do Efeito Estufa (GEE) na atmosfera, provocadas principalmente pela queima de combustíveis fósseis e pela mudança no uso do solo, tem estimulado a busca por alternativas que objetivam a mitigação dos efeitos do clima sobre a população e promovam o desenvolvimento sustentável (OLIVEIRA, 2013).

A Rio-92, o Protocolo de Quioto, as convenções sobre o clima, a comunidade científica, os governos e a sociedade civil organizada buscam ferramentas para harmonizar o desenvolvimento econômico com responsabilidade socioambiental (OLIVEIRA, 2013). O protocolo de Quioto, em vigor desde 2005, trouxe à comunidade global o conceito de Mecanismo de Desenvolvimento Limpo (MDL), um dos três mecanismos de flexibilização desenvolvidos como proposta de recompensar, financeiramente, os países que adotem práticas sustentáveis de uso dos recursos naturais com o objetivo de reduzir as emissões de carbono (OLIVEIRA, 2013).

O mecanismo de Redução de Emissão por Desmatamento e Degradação Florestal (REDD) é a ligação de mecanismos legais, ações governamentais e de tecnologias de exploração e produção que visam a redução das emissões de carbono provenientes do desmatamento e da degradação florestal por meio de incentivos positivos ou compensações financeiras (OLIVEIRA, 2013).

Entende-se o Código Florestal Brasileiro como mecanismo legal ou de comando/controle e como MDL, pode-se citar os sistemas agroflorestais (IPCC, 2007 apud OLIVEIRA, 2013). As práticas de florestamento, reflorestamento, manejo florestal e redução do desflorestamento surgem como MDL (OLIVEIRA, 2013).

No Protocolo de Quioto, os SAF são classificados como um Mecanismo de Desenvolvimento Limpo (NEPSTAD et al., 2010). Os SAF possuem elevado potencial para sequestro de carbono e a mitigação da emissão dos GEE (MUTUO et al., 2005).

Motta et al. (2000) destacaram que os sistemas agroflorestais são promissores à recuperação das áreas degradadas, alteradas, de reserva legal e de 
áreas de preservação permanentes, além do Mecanismo de Desenvolvimento Limpo (MDL) e a introdução dessas áreas em novos ciclos produtivos. O uso dos SAF para a restauração de passivos florestais, Áreas de Preservação Permanente (APP), Reservas Legais (RL), dentre outros, podem apresentar vantagens econômicas pelos retornos produtivos das culturas agrícolas nos primeiros anos, enquanto as árvores recompõem a paisagem (AMADOR, 2003; SABOGAL et al., 2006).

Segundo a legislação anterior - Lei no 4771, de 15 de setembro de 1965 (BRASIL, 1965), não era permitido o cultivo de quaisquer sistemas de produção em Área de Preservação Permanente (APP) e Reserva Legal (RL), sendo permitido apenas o manejo agroflorestal sustentável em Reservas Legais de pequenas propriedades rurais, o que restringia significativamente o perímetro agricultável de tais propriedades.

Com a publicação da Lei n 12.651, de 25 de maio de 2012, que institui o novo Código Florestal (BRASIL, 2012), essas definições mudaram. Ficou definido que pequenas propriedades rurais podem utilizar plantios de sistemas agroflorestais em suas APP e RL, desde que esses sistemas sejam submetidos a planos de manejo sustentáveis aprovados pelo órgão estadual do meio ambiente responsável.

\subsubsection{Sistemas agroflorestais na Amazônia: o caso de Tomé-Açu}

A região Norte do Brasil, que ocupa quase metade do território do país e detém a maior extensão de florestas quentes e úmidas do mundo, apresenta grande concentração e diversidade de SAF, que são, na maior parte, estabelecidos e manejados por meio do conhecimento popular socialmente importante, porém com baixo nível técnico (SILVA, 2013).

O uso de sistemas agroflorestais na Amazônia surgiu como uma opção sustentável, com possibilidade de auxiliar na redução do desmatamento, uma vez que quebra o ciclo da agricultura migratória, a qual, em função de períodos de pousio muito curtos para a recuperação dos solos, aumenta a pressão sobre as áreas de floresta primária (SMITH et al., 1998). Ferreira et al. (2009) realizaram uma pesquisa com cinquenta agricultores familiares e identificaram que nas áreas de adoção dos SAF o número de áreas preparadas através do sistema tradicional, de corte e queima, foi reduzido.

Com diversas finalidades e arranjos, os SAF têm sido trabalhados e incentivados como estratégias para o fortalecimento das unidades produtivas locais, buscando a melhoria da renda familiar (CALVI, 2009). 
A prática de SAF não é novidade, pois já era utilizada por comunidades indígenas, caboclas e ribeirinhas, para fins de subsistência, porém, os colonizadores europeus somente perceberam a sua importância muito tempo depois (BARROS et al., 2009).

Entre os diversos tipos de sistemas agroflorestais nas regiões tropicais são destacados os sistemas taungya, silvipastoris, quintais agroflorestais e os sistemas multiestratificados comerciais, sendo estes dois últimos bastante praticados na Amazônia (VIEIRA et al., 2007).

Os quintais agroflorestais são muito comuns na Amazônia (SILVA, 2013). Van Leeuwen e Gomes (2001) denominam os quintais agroflorestais como pomar caseiro. Dependendo da região, esses sistemas de produção podem receber outras denominações como terreiro, quintal, sítio, pomar doméstico ou horta caseira e miscelânea (VAN LEEUWEN; GOMES, 2001). Os quintais geralmente apresentam em sua composição árvores de muitas espécies diferentes, boa parte frutífera, a área varia entre 0,2 e 2,5 hectares, normalmente dentro do pomar é mantida uma pequena criação de aves (galinhas e patos). Para Noda S., Noda H. e Martins (2001), os quintais equivalem aos SAF multiestratificados encontrados nas propriedades dos agricultores familiares de terra firme da Amazônia Central.

Os SAF multiestratificados são praticados na Amazônia brasileira desde a década de 1970 pelos agricultores japoneses em Tomé-Açu, PA. Os primeiros sistemas agroflorestais implantados no município foram inseridos pelos agricultores nipo-brasileiros como estratégia de diversificação da produção e da redução dos riscos do monocultivo. Esses sistemas de produção surgiram a partir da busca por novas alternativas produtivas, em função da disseminação da fusariose (Fusarium solani f. sp. piperis) nos plantios de pimenta-do-reino (Piper nigrum L.), que surgiu em 1957 e passou a devastar os monocultivos de pimenta a partir da década de 1970, e da queda de preços decorrente da expansão desordenada dos plantios (HOMMA, 2004). A busca por novas alternativas econômicas fizeram com que sistemas consorciados, em rotação e sequencial, com cultivos perenes e anuais fossem adotados, com o objetivo de aproveitar áreas antes, durante e depois do plantio da pimenta-do-reino (HOMMA, 1996).

Barros et al. (2011) afirmam que a busca por novas alternativas de produção permite que os sistemas agroflorestais implantados em Tomé-Açu apresentem grandes perspectivas de expansão na região, visando a ocupação de áreas desmatadas, assim como a recuperação de áreas degradadas.

O município tem se destacado pela tradição do uso de sistemas agroflorestais com diferentes composições de espécies, formas e tamanhos, conforme o objetivo do agricultor, tornando-se um modelo base de produção 
diversificada, denominada atualmente como Sistema Agroflorestal de Tomé-Açu (SAFTA) (MATSUNAGA; HIRAMIZU, 2016).

O SAFTA permite a inclusão de uma diversidade de culturas, desde as anuais, semiperenes e florestais, gerando uma produção eficaz, desde o primeiro ano do sistema e ao longo dos anos, logo, obtém-se uma melhor distribuição de renda e trabalho durante o ano e ao longo dos anos, otimizando o uso da terra, o que contribui para o desenvolvimento sustentável das terras agrícolas da região (MATSUNAGA; HIRAMIZU, 2016). Os sistemas agroflorestais praticados em Tomé-Açu representam um caminho para um futuro melhor para a terra e para os trabalhadores que a utilizam para produzir (TAFNER JÚNIOR; SILVA, 2012).

Os SAF do município de Tomé-Açu têm no cacau e no cupuaçu as duas culturas perenes consideradas principais na rentabilidade dos sistemas e a pimenta do reino aparece na maioria das propriedades devido à tradição no cultivo e pelos altos rendimentos em curto prazo, mesmo enfrentando fases de declínio com preços mais baixos (MENDES, 2003). Segundo Barros et al. (2009), os SAF do município são formados, basicamente, por cultivos de pimenta-doreino, cacau, açaí e cupuaçu, combinados entre si e/ou com espécies frutíferas e florestais. Couto (2013) identificou que 90\% dos SAF de Tomé-Açu apresentam a pimenta-do-reino em seu arranjo, da mesma maneira que o cupuaçu e o açaí, o cacau está presente em $81 \%$ das propriedades. A mesma autora observou que os sistemas foram implantados a partir do monocultivo de pimenta já existente, sendo introduzidas ao longo do tempo as demais espécies frutíferas e florestais.

Segundo Carvalho (2008), a produção em SAF na Amazônia vem se desenvolvendo por meio de organização de pequenos produtores de base familiar, em associações ou cooperativas de produtores, geralmente localizados em áreas de difícil acesso e pouca infraestrutura.

Em Tomé-Açu não é diferente, pois no município existem diversas associações de produtores rurais (COUTO, 2013), com destaque para a Cooperativa Agrícola Mista de Tomé-Açu (CAMTA) e a Associação de Produtores e Produtoras de Agricultura Familiar do Município de Tomé-Açu (APPRAFAMTA).

A CAMTA desempenha um importante papel no desenvolvimento do município com a agroindustrialização da produção agrícola, além disso, oferece assistência técnica aos agricultores cooperados e não cooperados, mas que podem se tornar fornecedores da CAMTA. Assim, todos os agricultores conseguem produzir em maior quantidade e de forma eficiente.

A APPRAFAMTA foi fundada a exemplo da CAMTA, pelos agricultores familiares da comunidade de Santa Luzia, situada na zona rural do município, os 
quais passaram a adotar as experiências exitosas com SAF associados com novas alternativas de produção, beneficiamento e comercialização (COUTO, 2013).

\section{CONSIDERAÇÕES FINAIS}

A agricultura de corte e queima é a forma de cultivo predominante nos estabelecimentos agrícolas familiares na Amazônia. Por muito tempo, sua prática foi tratada como um sistema sustentável tendo em vista a rápida disponibilização de nutrientes para o solo e consequentemente a alta produtividade. No entanto, nos últimos anos, muitos estudos têm apontado os impactos negativos causados por essa prática, entre eles, a emissão de gases do efeito estufa e a redução na capacidade produtiva devido à diminuição no tempo de pousio, ocasionado pelo aumento populacional e pela necessidade de geração de alimentos. Com isso, novas formas de produção baseadas nos princípios da sustentabilidade surgiram, entre elas, o corte e trituração da capoeira e os sistemas agroflorestais.

Espera-se que as práticas de corte e trituração da capoeira e os sistemas agroflorestais sejam amplamente difundidos, a fim de proporcionar a utilização de áreas já desmatadas e abandonadas, utilizar as áreas para produzir mais e por mais tempo e diminuir a pressão sobre as áreas de floresta, para que possamos ter uma agricultura baseada no tripé da sustentabilidade, economicamente viável, socialmente justa e ambientalmente correta.

\section{REFERÊNCIAS}

ABDO, M. T. V. N.; VALERI, S. V.; MARTINS, A. L. M. Sistemas agroflorestais e agricultura familiar: uma parceria interessante. Revista Tecnologia \& Inovação Agropecuária, São Paulo, v. 1, n. 2, p. 50-59, 2008.

ALTIERI, M. A. Agroecologia: princípios e estratégias para a agricultura sustentável na América Latina do século XXI. 1989. Disponível em: <http:// webcache.googleusercontent.com/search?q=cache:tkI4-gAyqfcJ:comunidades. mda.gov.br/o/899012+agroecologia $+\mathrm{e}+$ revolu $\% \mathrm{C} 3 \% \mathrm{~A} 7 \% \mathrm{C} 3 \% \mathrm{~A} 3 \mathrm{o}+$ verde\&c $\mathrm{d}=21 \& \mathrm{hl}=\mathrm{pt}-\mathrm{BR} \& \mathrm{ct}=\mathrm{clnk} \& \mathrm{gl}=\mathrm{br}>$. Acesso em: 08 jan. 2016.

ALTIERI, M. A; ROSSET, P. Agroecologia versus substituição de insumos: uma contradição fundamental da agricultura sustentável. In: ALTIERI, M. A. Agroecologia: bases científicas para uma agricultura sustentável. Guaíba: Agropecuária, 2002. p. 321-346. 
ALTIERI, M. A. Linking ecologists and traditional farmers in the search for sustainable agriculture. Frontiers in Ecology and Environment. University of California, Berkeley, v. 1, n. 2, p. 35-42, 2004.

ALVES, L. M. Sistemas Agroflorestais (SAF's) na restauração de ambientes degradados. Programa de Pós-graduação em Ecologia Aplicada ao Manejo e Conservação de Recursos Naturais (PGECOL). UFJF, Juiz de Fora, MG, 2009. $18 \mathrm{p}$.

AMADOR, D. B. Restauração de ecossistemas com sistemas agroflorestais. In: KAGEYAMA, P. Y. et al. (Org.). Restauração ecológica de ecossistemas naturais. Botucatu: Fundação de Estudos e Pesquisas Agrícolas e Florestais, 2003. p. 333-340.

ARCO-VERDE, M. F. Sustentabilidade biofísica e socioeconômica de Sistemas Agroflorestais na Amazônia Brasileira. 2008. 209 f. Tese (Doutorado). Curso de Pós-graduação em Ciências Florestais, Universidade Federal do Paraná, Curitiba, 2008.

ARCO-VERDE, M. F; AMARO, G. Cálculo de Indicadores Financeiros para Sistemas Agroflorestais. Boa Vista, RR: Embrapa Roraima, 48p. 2012.

BARROS, A. V. L. de.; HOMMA, A. K. O.; TAKAMATSU, J. A.; TAKAMATSU, T.; KONAGANO, M. Evolução e percepção dos sistemas agroflorestais desenvolvidos pelos agricultores nipo-brasileiros do município de Tomé-Açu, estado do Pará. Amazônia: Ciência \& Desenvolvimento. Belém, volume 5, p. 121-151. 2009.

BARROS, A. V. L.; HOMMA, A. K. O.; SANTANA, A. C.; ARCO-VERDE, M. F.; MENDES, F. A. T. . Sistemas Agroflorestais Nipo-brasileiros do Município de Tomé-Açu, Pará: Formação e Percepção. In: HOMMA, A. K. O.; FERREIRA, A. DA S.; FREITAS M. C. DA S.; FRAXE, T, DE J. P. (Org.). Imigração Japonesa na Amazônia: Contribuição na agricultura e vínculo com o Desenvolvimento Regional. 1. ed. Manaus: Editora da Universidade Federal do Amazonas, 2011, p. 305-337.

BRASIL. Lei no 12.651, de 25 de maio de 2012. Diário Oficial da República Federativa do Brasil, Poder Executivo, Brasília, DF, 25 de maio. 2012. Lei no 4.771, de 15 de setembro de 1965. Diário Oficial da República

Federativa do Brasil, Poder Executivo, Brasília, DF, 15 de set. 1965. 
BRIENZA JÚNIOR. S.; DENICH, M.; FÖLSTER, H.; VLEK, P. L. G. Fallow vegetation enrichment with leguminous trees in the eastern amazon of Brazil: Trees performance. German-Brazilian Workshop on Neotropical Ecosystems Achievements and prospects of cooperative research Hamburg, $3-8$, p. 935-938, set. 2000.

CALVI, M. F. Fatores de adoção de sistemas agroflorestais por agricultores familiares do Município de Medicilândia, Pará. 2009. 122f. Dissertação (Mestrado) - Pós-Graduação em Agriculturas Amazônicas, Universidade Federal do Pará, Belém, 2009.

CAPORAL, F. R.; COSTABEBER, J. A. Agroecologia: alguns conceitos e princípios, 1. ed. Brasília: MDA/SAF/DATERIICA, 2007. 24 p.

CAPORAL, F. R.; PAUluS, G.; COSTABEBER J. A. Agroecologia: uma ciência do campo da complexidade. Brasília. 2009, 111 p.

CARVAlHO, O. M.; SILVA NETO, J. M.; CARVALHO, E. M.; PEREIRA, S. A. A Nova Economia Institucional - NEI e os Sistemas Agroflorestais - SAFs: um estudo com duas organizações agroflorestais na região amazônica. Palestra. In: XLVI Congresso da SOBER - Sociedade Brasileira de Economia, Administração e Sociologia Rural. Rio Branco - AC, 2008. Disponível em <http://www.sober.org.br/palestra/9/785.pdf>. Acesso em: 27 fev. 2016.

CATTANEO, A. Balancing agricultural development and deforestation in the Brazilian Amazon. Washington: IFPRI, 2002. 146p.

COELHO, R. F. R.; OLIVEIRA, V. C.; CARVALHO, C. J. R.; SÁ, T. D. de A. Fluxo de nitrogênio e fósforo pela deposição de liteira em sistemas de produção agrícola de corte/queima e corte/trituração/manejo de capoeira, na Amazônia oriental. In: CONGRESSO BRASILEIRO DE SISTEMAS AGROFLORESTAIS, 5., 2004, Curitiba. Anais... Colombo: EMBRAPA, p. 559-561. 2004.

CORRÊA, M. J. P. Levantamento da flora espontânea na cultura do feijão-caupi sob manejo de capoeira triturada no município de Santa Luzia do Paruá - MA. Cadernos de Agroecologia. v. 6, n. 2, 2011. 5 p.

COSTABEBER, J. A. Acción colectiva y procesos de transición agroecológica en Rio Grande do Sul, Brasil. Córdoba, 1998. 422f. (Tese de Doutorado) Programa de Doctorado en Agroecología, Campesinado e Historia, ISEC-ETSIAN, Universidad de Córdoba, España, 1998. 
COUTO, M. C. de M. Beneficiamento e comercialização dos produtos dos sistemas agroflorestais na Amazônia, Comunidade Santa Luzia, ToméAçu, Pará. 2013. 138f. Dissertação (Mestrado em Agriculturas e Desenvolvimento Sustentável) - Universidade Federal do Pará, Belém, 2013.

DENICH, M.; KANASHIRO, M.; VLEK, P. L. G. The potential and dynamics of carbon sequestration in traditional and modified fallow systems of the Eastern Amazon region, Brazil. In: LAL, R.; KIMBLE, J. M.; STEWART, B. A. (Ed.) Global climate change and tropical ecosystems. Boca Raton: CRC, 1999. p. 213-229.

ENGEL, V. L. Sistemas agroflorestais: conceitos e aplicações. In: Introdução aos Sistemas Agroflorestais. Botucatu: FEPAF, 1999. 70 p.

FEARNSIDE, P. M. Limiting factors for development for agriculture and ranching in Brazilian Amazonian. Revista Brasileira de Biologia, v. 57, n.4, p. 531-549. 1997.

FERREIRA, J. H. O.; KATO, O. R.; FREITAS, A.; GREVINELL, J. G.; PISSATTO, M. Sistemas agroflorestais na agricultura familiar como alternativa para diversificação da produção e redução de queimadas no Nordeste Paraense. In. CONGRESSO BRASILEIRO DE SISTEMAS AGROFLORESTAIS, 7., 2009. Anais... EMBRAPA, 2009.

FONTES, M. A.; RIBEIRO, G. T.; SIQUEIRA, E. R.; SIQUEIRA, P. Z. R.; RABANAL, J. E. M. Sistema agroflorestal sucessional como estilo produtivo para agricultura familiar em território de identidade rural, em Sergipe, Brasil. Revista Brasileira de Agroecologia, v. 8, n. 2, p. 112-120, 2013.

FREITAS, J. L.; SANTOS, E. S.; LIMA E SILVA, R. B.; SILVA, T. L. Comparação e análise de sistemas de uso da terra de agricultores familiares na Amazônia. Biota Amazônia, Macapá, v. 3, n. 1, p. 100-108, 2013.

FREITAS, J. P. de.; MEDEIROS, M. C. S.; SILVA, J. A. L.; FREITAS, F. E. de; NETO, M. F. da S. Agroecologia como alternativa para mudanças de um estilo de agricultura convencional para uma agricultura de base familiar: o caso do assentamento Santo Antonio no município de Cajazeiras-PB. CAMPOTERRITÓRIO: Revista de Geografia Agrária, v. 9, n. 17, p. 436-468, abr. 2014.

GAMA, M. A. P. Dinâmica do fósforo em solo submetido a sistemas de preparo alternativos ao corte e queima no Nordeste Paraense. 2002. $96 f$. Tese (Doutorado) ESALQ, Piracicaba, 2002. 
GLIESSMAN, S. R. Agroecologia: processos ecológicos em agricultura sustentável. Porto Alegre: Editora UFRGS, 2001. 653 p.

HOLSCHER, D.; MOLLER, M. R. F.; DENICH, M.; FOLSTER, H. Nutrient input-output budget of shifting agriculture in Eastern Amazonia. Nutrient Cycling in Agroecosystems, 47, p. 49-57, 1997.

HOMMA, A. K. O. Dinâmica dos sistemas agroflorestais: o caso da Colônia Agrícola de Tomé-Açu, Pará. Revista Instituto de Estudos Superiores da Amazônia, v. 2, p. 57-65, 2004.

Modernization and technological dualism in the extractive economy in Amazonia. In: PÉREZ, M. R.; ARNOLD, J. E. M. (Ed.) Current issues in nontimber forest products research. Bogor, Indonesia: Cifor/ODA, 1996. p.5981.

HURTIENNE, T. Agricultura familiar e desenvolvimento rural sustentável na Amazônia. Novos Cadernos NAEA, Belém: NAEA/UFPA, v. 8, n. 1, 2005. $71 \mathrm{p}$.

JESUS, P. P.; SILVA, J. S.; MARTINS, J. P.; RIBEIRO, D. D.; ASSUNÇÃO, H. F. Transição agroecológica na agricultura familiar: relato de experiência em Goiás e Distrito Federal. CAMPO-TERRITÓRIO: revista de geografia agrária, v. 6, n. 11, p. 363-375. fev., 2011.

KANASHIRO, M.; DENICH, M. Possibilidades de utilização e manejo adequado de áreas alteradas e abandonadas na Amazônia brasileira. Brasília, DF: MCT/CNPq, 1998, 157 p.

KATO, M. S. A. Fire free land preparation as an atlernative to slash-andburn agriculture in the Bragantina region: crop performance and Phosphorus dynamics. Göttingen: Cuvillier, 1998. 144 p.

KATO, M. S. A.; KATO, O. R.; DENICH, M.; VLEK, P. L. G. Fire free alternatives to slash-and-burn for shifting cultivation in the eastern Amazon region: The role of fertilizers. Field Crops Research, Amsterdam, v.62, n.23, p. 225-237. 1999.

KATO, O. R.; SECCO, N. B. Intensificando o cultivo em sistemas agroflorestais sucessionais. In: CONGRESSO BRASILEIRO DE SISTEMAS AGROFLORESTAIS, 5. Ilhéus, Anais... Ilhéus: CBSA. Documentos, 98, p. 111 113. 2004.

KATO, O. R.; KATO, M. do S. A.; CARVALHO, C. J. R. de; FIGUEIREDO, R. de O.; CAMARÃO, A. P.; SÁ, T. D. de A. Plantio direto na capoeira: uma 
alternativa com base no manejo de recursos naturais. In: WADT, P. G. S. (Org.). Sistema plantio direto e controle de erosão no Estado do Acre. Rio Branco: Embrapa Acre, 2007. p. 79-111.

KATO, O. R.; VASCONCELOS, S. S.; FIGUEIREDO, R. O.; CARVALHO, C. J. R.; SÁ, T. D. A.; SHIMIZU, M. K. Agricultura sem queima: uma proposta de recuperação de áreas degradadas com sistemas agroflorestais sequenciais. In: LEITE, L. F. C.; MACIEL, G. A.; ARAÚJO, A. S. F. (Ed.). Agricultura Conservacionista no Brasil. Brasília: Embrapa, 2014. p. 189-216.

LAMÔNICA, K. R.; BARROSO, D. G. Sistemas agroflorestais: aspectos básicos e recomendações. Manual Técnico 7. Niterói - RJ, 2008. 15 p.

MARCOLAN, A. L.; LOCATELLI, M. FERNANDES, S. R. Atributos químicos e físicos de um Latossolo e rendimento de milho em diferentes sistemas de manejo da capoeira. Comunicado Técnico 352, Embrapa, Porto Velho - RO, 2009, p. 6.

MARTINS, S. V. Recuperação de áreas degradadas: como recuperar áreas de preservação permanente, voçorocas, taludes rodoviários e áreas de mineração. 3. ed. Viçosa: Aprenda Fácil, 2013. 264 p.

MAY, P. H.; TROVATTO, C. M. M. Manual agroflorestal para a Mata Atlântica. Brasília: MDA/SAF, 2008. 196p.

MATSUnAGA, A. T.; HIRAMIZU, N. H. Análise sócio econômica e de produtividade de um sistema agroflorestal multiestratificado no Município de Tomé-Açu/PA. 2016. 43f. Trabalho de Conclusão de Curso (Graduação em Engenharia Florestal) - Universidade Federal Rural da Amazônia, 2016.

MENDES, F. A. T. Avaliação de modelos simulados de sistemas agroflorestais em pequenas propriedades cacaueiras selecionadas no Município de Tomé-Açu, no Estado do Pará. Informe GEPEC, v. 7, n. 1, 2003. 19p.

MEDRADO, M. J. S. Sistemas agroflorestais: aspectos básicos e indicações. In: GALVÃO, A. P. M. (Org.). Reflorestamento de propriedades rurais para fins produtivos e ambientais: um guia para ações municipais e regionais. Brasília: Embrapa Comunicação para Transferência de Tecnologias; Colombo, PR: Embrapa Floresta. 2000. p. 269-312.

MMA - Ministério do Meio Ambiente. Agricultura Sustentável. Brasília, 2000. 157 p. 
MIRANDA, P. S.; RODRIGUES, W. Sistema Agroflorestal "agricultura em andares." Belém: UFPA, NUMA, POEMA, 1999. 102 p.

MOTTA, R. S. FERRAZ, C.; YOUNG, C. E. F.; AUSTIN, D.; FAETH, P. O mecanismo de desenvolvimento limpo e o financiamento do desenvolvimento sustentável no Brasil. Rio de Janeiro: IPEA, 2000. 51 p. Disponível em: <http:/ /www.ipea.gov.br>. Acesso em 15 mar. 2016.

MUTUO, P. K.; CADISCH, G.; ALBRECHT, A.; PALM, C. A.; VERCHOT, L. Potential of agroforestry for carbon sequestration and mitigation of greenhouse gas emissions from soils in the tropics. Nutrient Cycling in Agroecosystems, v. 71, p. 43-54, 2005.

NAIR, P. K. R. Agroforestry systems in the tropics. Dordrecht: Boston: Kluwer Academic Publishers. ICRAF. 1989, 664 p.

NEPSTAD, D.; STICKLER, C. M.; CATTANEO, A.; JOHNS, T. Brazil's emerging sectoral framework for reducing emissions from deforestation and degradation and the potential to deliver greenhouse gas emissions reductions from avoided deforestation in the Amazon's Xingu river basin. California, EUA: Electric Power Research Institute, 2010. 158 p.

NORONHA, A. F. B. Agricultura familiar, extensão rural e sistemas agroflorestais: a experiência do CAV no Alto Jequitinhonha. 2008. $119 f$. Dissertação (Mestrado em Administração) - Universidade Federal de Lavras, Lavras - MG, 2008.

NODA, S. do N.; NODA, H.; MARTINS, L. L. U. Utilização e apropriação das terras por agricultura familiar Amazonense de Várzeas. In: DIEGUES, A. C; MOREIRA, A. de C. C. (Org.). Espaços e recursos naturais de uso comum. São Paulo: Núcleo de Apoio à Pesquisa sobre Populações Humanas e Áreas Úmidas Brasileiras, 2001. p. 181-204.

NUNES DA SILVA, J.; MATTTOS, J. S.; DINIZ, P. C. O.; VASCONCELOS, G. O. S. Transição Agroecológica em Assentamentos Rurais: o processo inicial no assentamento Chico Mendes III/PE-Brasil. Revista Brasileira de Agroecologia, v. 4, n. 2, p. 3022-3025, nov. 2009.

OLIVEIRA, D. M. Q. de. Avaliação econômica de sistemas agroflorestais no Nordeste Paraense: os sistemas agroflorestais como instrumento de política pública de desenvolvimento socioeconômico e ambiental regional. 2013. 162 f. Dissertação (Mestrado em Ciências Ambientais) - Universidade Federal Rural da Amazônia, Belém, 2013. 
OLIVEIRA, J. S. R.; KATO, O. R.; OLIVEIRA, T. F.; QUEIRÓZ, J.; CARDOSO, R. Agricultura familiar e safs: produção com conservação na Amazônia Oriental, nordeste paraense. In: CONGRESSO BRASILEIRO DE SISTEMAS DE PRODUÇÃO. Agricultura familiar, políticas públicas e inclusão social. 2007. Anais... Fortaleza: Embrapa Agroindústria Tropical, 2007.

PALUDO, R.; COSTABEBER, J. A. Sistemas agroflorestais como estratégia de desenvolvimento rural em diferentes biomas brasileiros. Revista Brasileira de Agroecologia, v. 7, n. 2, p. 63-76, 2012.

PEREIRA, C. A.; VIEIRA, I. C. G. A importância das florestas secundárias e os impactos de sua substituição por plantios mecanizados de grãos na Amazônia. Interciência, v. 26, p. 337-341, 2001.

SÁ, T. D. A.; KATO, O. R.; CARVALHO, C. J. R.; FIGUEIREDO, R. O. Queimar ou não queimar? De como produzir na Amazônia sem queimar. Revista USP, São Paulo, v. 72, p. 90-97, 2006.

SABOGAL, C. Silvicultura na Amazônia Brasileira: avaliação de experiências e recomendações para implementação e melhoria dos sistemas. Belém: CIFOR, 2006, 190 p.

SANTOS, J. C. Sustentabilidade socioeconômica e ambiental de sistemas de uso da terra da agricultura familiar no estado do Acre. 2008. 182f. Tese (Doutorado) - Universidade Federal de Viçosa, Viçosa, MG, 2008.

SAMPAIO, C. A.; KATO, O. R.; NASCIMENTO E SILVA, D. Corte e trituração da capoeira sem queima como alternativa de uso da terra, rumo à sustentabilidade florestal: o caso Tipitamba em Igarapé-Açu/Pará. In: ENGEMA - Encontro Nacional Sobre Gestão Empresarial e Meio Ambiente, 9, 2007, Curitiba, PR. Anais... Curitiba, PR, 2007.

SAMPAIO, C. A.; KATO, O. R.; NASCIMENTO E SILVA, D. Sistema de corte e trituração da capoeira sem queima como alternativa de uso da terra, rumo à sustentabilidade florestal no nordeste paraense. RGSA - Revista de Gestão Social e Ambiental. v. 2, n. 1, p. 41-53.Jan. - Abr. 2008.

SILVA, I. C. Sistemas agroflorestais, conceitos e métodos. Itabuna: SBSAF, 2013. 308 p.

SILVA, I. C. Sistemas Agroflorestais no Brasil: Aspectos Conceituais e Conjunturais. In: GIMÉNEZ, A. M.; BOLZÓN, G. I. (Org.). Educación e Investigación Forestal Para un Equilibrio Vital: Cooperación Binacional Brasil Argentina. 1. ed. Córdoba (Argentina): Brujas, v. 1. 2014. p. 197-215. 
SMITH, N. DUBOIS, J. C. L.; CURRENT, D.; LUTZ, E.; CLEMENT, C. Experiências Agroflorestais na Amazônia Brasileira: Restrições e oportunidades. Programa Piloto para a Proteção das Florestas Tropicais do Brasil, Brasília, Brasil, 1998. 146p.

SOUZA, C. M. de A.; FREITAS, F. dos S.; CARVALHO, C. J. R. de; VASCONCELOS, S. S.; KATO, O. R. Atributos físicos do solo em sistemas agroflorestais sequenciais no município de Igarapé-Açu, Pará. In: CONGRESSO BRASILEIRO DE SISTEMAS AGROFLORESTAIS, 8. Belém, 2011. Anais... Belém: SBSAF; Embrapa Amazônia Oriental; UFRA; CEPLAC; EMATER; ICRAF, 2011.

TAFNER JÚNIOR, A. W.; SILVA, F. C. Atuação da Cooperativa Agrícola Mista de Tomé-Açu (CAMTA) no Mercado Promovendo o Cooperativismo e a Sustentabilidade na Amazônia. In: ENCONTRO NACIONAL DA ASSOCIAÇÃO NACIONAL DE PÓS-GRADUAÇÃO E PESQUISA EM MEIO AMBIENTE E SOCIEDADE, 6. Belém, 2012. Anais... Belém: ANPPAS, 2012.

TRINDADE, E. F. DA S.; KATO, O. R.; CARVALHO, E. J. M.; SERAFIM, E. C. DA S. Disponibilidade de fósforo em solos manejados com e sem queima no Nordeste paraense. Amazônia: Ciência \& Desenvolvimento, Belém, v. 6, n. 12, p. 7-19. jan./jun. 2011.

VANDERMEER, J. The Ecology of Intercropping. Cambridge: Cambridge University Press, 1989.237 p.

VAN LEEUWEN, J.; GOMES, J. B. M. O pomar caseiro na região de Manaus, Amazonas, um importante sistema agroflorestal tradicional. Brasília: INPA, 2001. Disponível em: < http://www.inpa.gov.br/cpca/johapomar.html>. Acesso em: 18 fev. 2016.

VIEIRA, T. A.; ROSA, L. S.; VASCONCELOS, P. S. S.; SANTOS, M. M.; MODESTO, R. S. Sistemas agroflorestais em áreas de agricultores familiares em Igarapé-Açu, Pará: caracterização florística, implantação e manejo. Acta Amazônica, Manaus, v. 37, n.4, p.549-558, 2007.

VIEIRA, T. A.; ROSA L. S.; MODESTO, R. S.; SANTOS M. M. Gênero e Sistemas Agroflorestais: O Caso de Igarapé-Açu, Pará, Brasil. Revista Ciências Agrárias, Belém, n. 50, p. 143-154, jul./dez. 2008. 